\title{
LA RELACIÓN ENTRE EL DERECHO INTERNACIONAL PÚBLICO Y EL DERECHO PETROLERO: ESTUDIO DEL CASO ENTRE TIMOR- LESTE Y AUSTRALIA
}

\section{ARTÍCULO ORIGINAL}

PEREIRA, Jeremias ${ }^{1}$

PITHAN, Lívia Haygert ${ }^{2}$

PEREIRA, Jeremias. PITHAN, Lívia Haygert. La relación entre el derecho internacional público y el derecho petrolero: Estudio del caso entre Timor-Leste y Australia. Revista científica multidisciplinaria base de conocimiento. año 04, Ed. 12, Vol. 02, págs. 31-51. diciembre de 2019. ISSN: 2448-0959, Enlace de acceso: https://www.nucleodoconhecimento.com.br/ley/derecho-publico-internacional

\section{RESUMEN}

Este artículo tiene como objetivo analizar la Ley del Mar y el Petróleo para comprender las razones que generaron, durante más de una década, el conflicto entre Timor-Leste y Australia con respecto a la definición de fronteras marítimas definitivas. Timor-Leste ya ha sido explotado e invadido por varias naciones. Debido a la abundancia de petróleo y gas natural, sufrió obtener la independencia en 2002, así como luchó por disfrutar de su territorio marítimo hasta 2018 , de este nuevo contexto del tratado de frontera marítima firmado entre Timor-Leste y el Australia. La línea de equidistancia mediana fue el parámetro utilizado para definir las fronteras timorenses definitivas, otorgando el derecho a disfrutar de su territorio marítimo. El pacto definitivo sobre las fronteras ha contribuido en gran medida al desarrollo de Timor-Leste, debido a la explotación de las riquezas marinas, además de reconocer la necesidad del país de

1 Facultad de Derecho Académico, Facultad de Derecho, Pontificia Universidad Católica de Rio Grande do Sul - PUC-RS.

${ }^{2}$ Consejero. Doctor en Derecho Privado. Máster en Derecho. Licenciado en Derecho. 
que las compañías petroleras ayuden en la evolución de Timor-Leste de una manera específica y puntual. Esto debe ser ratificado ahora por los parlamentos nacionales de ambos países. Está previsto que el proceso de ratificación finalice en 2019. TimorLeste está tratando actualmente negociar sus fronteras marítimas con Indonesia, pero éstas han sido suspendidas durante el proceso de conciliación obligatoria con Australia. Ahora que este proceso ha terminado, los dos países pueden reanudar sus debates de nuevo.

Palabras clave: Derecho petrolero, derecho internacional, derecho del mar.

\section{INTRODUCCIÓN}

Durante más de una década, Australia y Timor-Leste han discrepado con las fronteras marítimas de cada uno de estos Estados. La controversia tiene lugar debido al derecho a la exploración petrolera y otras riquezas marítimas y a los obstáculos al desarrollo económico y político de Timor-Leste, después de un tratado firmado con Australia. Así, este artículo se desarrolla en el ámbito del derecho internacional público, específicamente en el área del Derecho del Petróleo.

Se cuestiona si el tratado entre Australia y Timor-Leste, sobre la definición de las fronteras marítimas, ha sido equilibrado, preservando plenamente el derecho de timorense. ¿Cuáles son los obstáculos para evitar que esta nación sea explotada desproporcionadamente por otras naciones y pueda desarrollarse a partir de 2019 ?

La pertinencia de esta investigación se justifica por el hecho de que la necesidad de respetar las fronteras marítimas de Timor-leste por parte de Australia está justificada. En el siglo XXI, a pesar de la existencia del derecho internacional y del derecho petrolero, Australia no tenía ningún interés en llevar a cabo un Tratado en el que se reconociera el derecho de timor-leste a recibir el porcentaje adecuado para la exploración petrolera territorio marítimo. La fragilidad económica histórica del país con mucho menos espacio terrestre que la gente de mar lo ha convertido en el blanco de la explotación de países como Indonesia y Australia. Aunque en 2018 se ha existido un Tratado permanente entre Timor-Leste y Australia, es necesario explorar varios 
documentos jurídicos relativos a la Ley del Mar y del Petróleo para construir fundamentos jurídicos internacionales, con el objetivo de multiplicarse los instrumentos de defensa contra otras naciones que pretenden explotar indebidamente el espacio territorial de Timor-Leste, debido a la actual fragilidad económica. ${ }^{[3]}$

Timor-Leste, hasta 1975, perteneció a Portugal, sus colonos. A partir de 1976, Indonesia lo invadió y comenzó a explotarlo, y sólo con la ayuda de las Naciones Unidas (ONU) este país eligió a su primer presidente de la república en 2001, convirtiéndose en un estado independiente y miembro de la ONU en 2002. A pesar de la independencia, Timor-Leste sufrió la tiranía de Australia al no recibir recursos financieros para la explotación de su territorio marítimo. Portugal, Indonesia y Australia nunca han invertido adecuadamente en Timor-Leste, aunque recaudaron millones de dólares de la extracción de petróleo en esa región, así como de otras riquezas. Debido a décadas de bajas inversiones financieras, la nación timorense necesita desarrollarse política y legalmente para poder ocurrir en el desarrollo económico. ${ }^{[4]}$

El objetivo general de este artículo científico es analizar el derecho público internacional y petrolero para comprender las razones que generaron hace más de una década el conflicto entre Timor-Leste y Australia en las fronteras marítimas. Para comprender el problema que rodea el territorio marítimo de Timor-Leste, se han esbozado varios objetivos específicos, como

a) presentar una visión general, visión política, histórica, jurídica y económica de Timor-Leste y su relación con Australia;

b) examinar el derecho internacional relativo al mar;

c) explotar el Derecho al Petróleo;

(d) analizar el tratado en las fronteras entre Timor-Leste y Australia.

Este artículo tiene su desarrollo dividido en cuatro partes: las posibilidades de evolución político-social, histórica, jurídica y económica de Timor-Leste se analizarán a lo largo de la investigación para lograr, analizar y verificar si el Tratado entre Australia y Timor-Leste contribuirán, de hecho, al avance de la sociedad timorense. A 
partir de esta información, será necesario comprender las razones que llevaron al pueblo de Timor-Leste a tener un bajo nivel de desarrollo en varias áreas.

El primer capítulo trata de los aspectos históricos y geográficos, además de la explotación de Timor-Leste por otras naciones, en un contexto histórico, de modo que se entiendan las razones del contexto jurídico, económico, político y social actual de este país.

En el segundo capítulo, se exploran aspectos en las fronteras del mar de Timor-Leste y la importancia de las relaciones internacionales para ese país. Este análisis tiene la función de observar los factores que favorecen al pueblo timorense para ser víctima de nuevo por los exploradores, debido a su fragilidad económica hoy en día. Para entender los mecanismos de defensa de un Estado en relación con los ataques marítimos, es necesario abordar el derecho internacional del mar. Esta parte del derecho internacional se ocupa de las normas y principios acordados internacionalmente relacionados con la propiedad, el uso, la explotación y la protección del mar y sus recursos en todo el mundo.. ${ }^{[5]}$

En el tercer capítulo se estudiará el concepto y la importancia del petróleo y su relevancia para el desarrollo de las naciones que tienen un enorme espacio territorial marítimo y un pequeño espacio terrestre, como Timor-Leste.

El petróleo fue descubierto en el siglo XIX y, desde sus inicios, ha habido importantes transformaciones en la humanidad, es una mezcla homogénea de compuestos orgánicos, principalmente hidrocarburos, insolubles en agua. Esta fuente de alimentación también se conoce como cruda. Desde 1859, ha sido considerado como un tesoro y, en el siglo XXI, es ferozmente codiciado por el papel relevante que desempeña en el mundo moderno. La búsqueda desenfrenada de Australia e Indonesia para el poder y el desarrollo económico ha dado lugar a varios conflictos con Timor-Leste debido a la ambición de algunos países de explotar el territorio marítimo que no les pertenecía. Es extremadamente importante entender cómo se produce la extracción de petróleo, así como recursos como el gas natural, para 
entender las razones que llevaron a una explotación indebida durante décadas de petróleo timorense. [6]

Posteriormente, los obstáculos al desarrollo de Timor-Leste se presentan en el cuarto capítulo. La relación con la comunidad internacional es extremadamente relevante para el desarrollo de este país. Los avances en el ámbito jurídico y político son esenciales para la evolución económica. Las empresas encargadas de explotar los recursos naturales del territorio marítimo deben negociar con profesionales timorenses preparados y capacitados para que los acuerdos ofrezcan muchas ventajas a TimorLeste. ${ }^{[7]}$

El presente estudio no pretende agotar todas las cuestiones, sino estimular los debates sobre el conflicto entre Timor-Leste y Australia. La técnica de investigación utilizada en este trabajo consistirá en la investigación bibliográfica, a través del análisis de doctrinas, artículos científicos, bibliotecas virtuales, así como la investigación en textos jurídicos de sitios web reconocidos como vehículos de información acreditado por el gobierno de Timor-Leste. El método adoptado será el proceso inductivo por el cual el estudiante, a través del estudio de varias posiciones de adoctrinadores, partirá de varios entendimientos particulares de ciertos autores, para llegar a varias conclusiones generales. Se llevará a cabo una exploración bibliográfica en relación con el tema, específicamente, con cada subcapítulo del resumen para lograr una conclusión general del problema. ${ }^{[8]}$

\section{TIMOR-LESTE, GEOGRAPHY, HISTORIA, ECONOMIA Y POLITICA}

La República Democrática de Timor-Leste es un país costero. Sus principales productos económicos son ñame, maíz, café, humo, caucho, sándalo blanco, ganado, cerdos, búfalos, entre otros. Este país se encuentra en la isla de Timor y tiene fronteras con Indonesia y Australia. Su territorio corresponde a secciones de esta isla, ya que en 1975, la época de la independencia de Portugal, la otra mitad del archipiélago ya no pertenecía al dominio portugués. Debido a esta situación, actualmente hay una parte de la isla que es el territorio de Indonesia. Se encuentra en el sudeste asiático, en el extremo sur del archipiélago indonesio, al noroeste de Australia, cerca de 
Oceanía. Al sur, se encuentra a 250 a 400 millas náuticas a través del mar de Timor con el continente australiano.

El territorio marítimo de este país, que tiene una abundancia de petróleo y gas natural, siempre ha atraído la codicia de los diversos países. Los tratados e invasiones que perjudicaron a los timorenses en diversos períodos históricos provienen del deseo de invadir y asumir el cargo para convertirse en una autoridad legítima para llevar a cabo la explotación del mar de Timor-Leste. Con el fin de obtener una ventaja, Australia fue el único país del mundo que reconoció oficialmente la anexión ilegal de Timor-Leste por Indonesia en la década de 1970, aunque hay una resolución del Consejo de Seguridad de la Asamblea de las Naciones Unidas Naciones Unidas que condenaron esta invasión. ${ }^{[9]}$

Figura 1 - Image caption Las fronteras marítimas de Timor-Leste

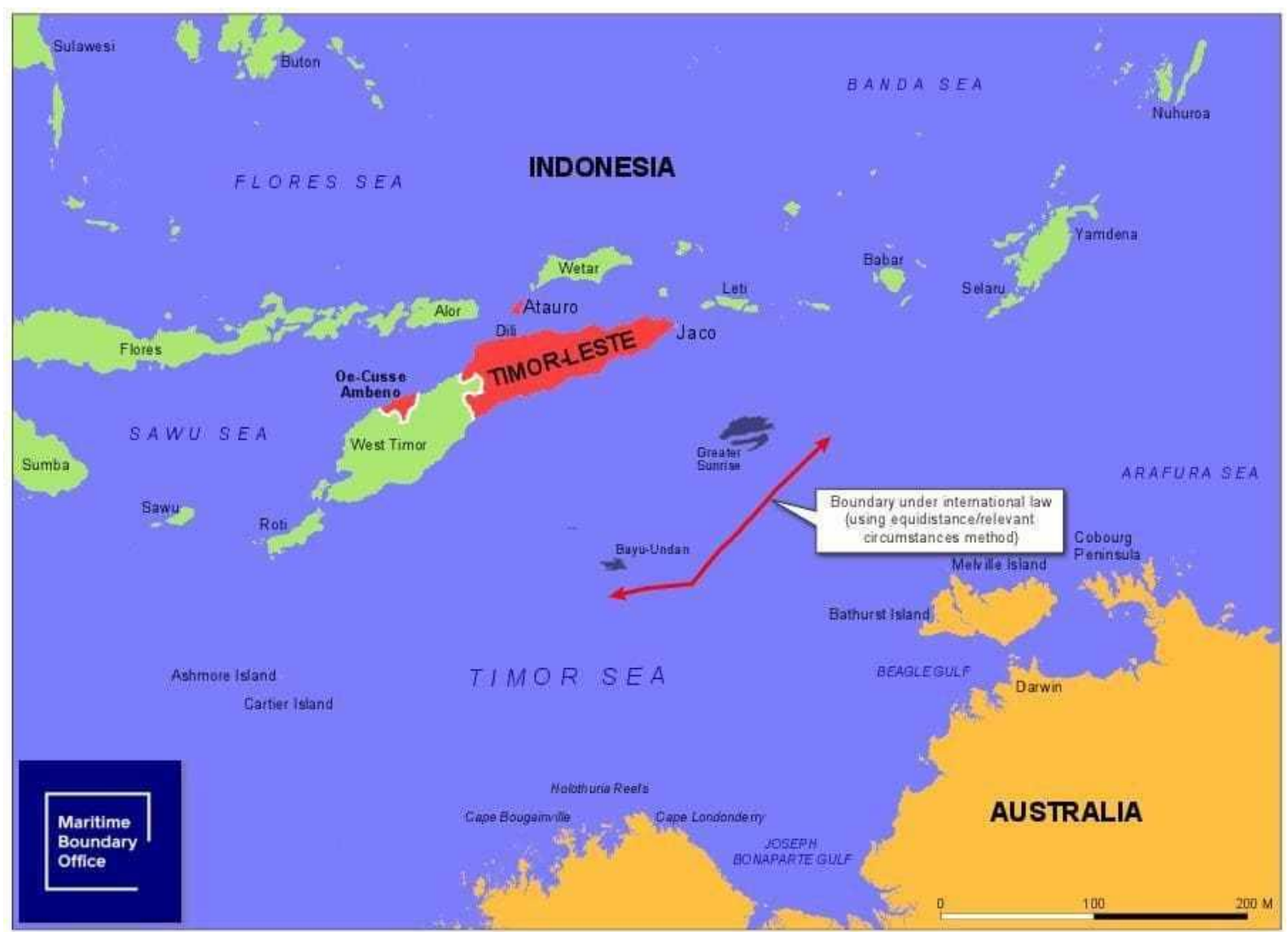

Fuente: Oficina de Límites Marítimos (20[10]) 
18)Timor-Leste ya ha sido explorada por Portugal, Japón, Indonesia y Australia en diferentes períodos. El contexto histórico de esta república es un factor que revela las causas de la actual situación social, política y económica de esta nación. Este país, que tiene un pequeño territorio terrestre y aproximadamente un millón de habitantes, necesita desarrollarse mucho en varias áreas porque es un país joven. Portugal fue el dominador de Timor-Leste desde 1515 hasta 1975 e invirtió poco en su crecimiento. De 1942 a 1945, en la Segunda Guerra Mundial, fue ocupada por Japón, pero pronto los portugueses recuperaron la autoridad de esta colonia. En abril de 1975, un movimiento político de las fuerzas armadas, popularmente conocido como 3D, surgió en Portugal, con el propósito de descolonizar, democratizar y desarrollar. Durante este período, en Timor-Leste nació un movimiento revolucionario conocido como FRETILIN, Frente Revolucionario de Timor-Leste Independiente. El 28 de noviembre de 1975, su independencia ocurrió, impulsada por el Movimiento de los Timoreses. La independencia se observó sólo durante diez días. ${ }^{[11]}$

Indonesia, en julio de 1975, invadió Timor-Leste, permaneciendo aproximadamente durante veintiséis años en ese territorio, en un momento en que se produjeron muchas muertes por enfermedades y escasez de alimentos. La comunidad internacional se vio conmovida por el genocidio que ocurrió allí. En 1999, la ONU, junto con Portugal, negrató un acuerdo con Indonesia, que se ocupaba de la posibilidad de celebrar un referéndum. En agosto de 1999, Timorese optó por la independencia con mayoría de votos, ya que el $78 \%$ de la población ya no aceptaba la masacre que sufrieron. Pero los dominadores no aceptaron la liberación. El personal militar indonesio torturó y masacró al pueblo. Muchos timorenses huyeron a la parte occidental de la isla, mientras que todo lo que se construyó a lo largo de la invasión fue destruido en ese país. Con el fin de controlar la masacre, la ONU adoptó la Resolución 1246 de agosto de 1999 para establecer una fuerza multinacional para estabilizar la situación. Después de la retirada de Indonesia, Timor-Leste se convirtió en el receptor de ayuda de la comunidad internacional, ya que había pérdidas humanas y materiales incalculables. El 20 de mayo de 2002, con ayuda, se restauró la independencia de la República Democrática de Timor-Leste, observando el primer gobierno elegido democráticamente. ${ }^{[12]}$ 
El interés de Australia por Timor-Leste no es nada nuevo. Los australianos tenían información de que en el mar de Timor-Leste había mucho gas y petróleo. Desde el descubrimiento en 1960 de que ha habido riqueza en el Mar de Timor gobiernos extranjeros han tratado de dominar la isla. En la década de 1970, Australia fue el único país que reconoció que la mitad occidental de la isla de Timor pertenecía a Indonesia. Resulta que en 1970, una compañía australiana llamada Woodside Petroleum encontró una enorme reserva de gas en la región conocida como The Sunrise and Troubadour Fields o Greater Sunrise. ${ }^{[13]} \mathrm{La}$ intención de negociar por ventajas territoriales fue una de las razones por las que los australianos ignoraron la opinión negativa de la comunidad internacional, que no estaba de acuerdo con la conducta de Indonesia de invadir la parte occidental de la isla de Timor. Interesados en obtener beneficios del descubrimiento de la riqueza en el Mar de Timor-Leste, Indonesia y Australia firmaron el tratado. Este documento se refería a las fronteras marítimas entre los dos países, pero Australia tomó el territorio en el que se encontraban las reservas de gas. Insatisfecho con el Tratado que firmó en 1975 Indonesia invadió Australia para obtener un porcentaje sobre la explotación de los recursos gasosos en esa región. Los timorenses no estuvieron de acuerdo con el tratado que compartía la riqueza de su territorio entre Indonesia y Australia, pero las dos naciones extranjeras involucradas en el acuerdo internacional ignoraron la posición mundial, contrariamente a su pacto. El 20 de mayo de 2002, fecha del restablecimiento de la independencia de Timorleste, el país trató de tomar posesión del territorio que tenía derecho a ello. Timor ya no pertenecía a Indonesia. Los tratados que se habían acordado antes de la independencia ya no eran valiosos. ${ }^{[14]}$

Australia, en 2002, con el objetivo de seguir dominando el territorio marítimo que pertenecería a Timor-Leste, se retiró de todos los procedimientos fronterizos vinculantes de los que formaba parte. En 2006, hubo un Tratado entre Australia y Timor-Leste sobre determinados ajustes marítimos en el mar de Timor, un acuerdo que desagradó a los timorenses porque sirvió para evitar cambios en las negociaciones legales o en las acciones legales durante cincuenta años. Fue en 2016 cuando las personas que se sintieron perjudicadas por el Tratado notificaron a los australianos que resolvería el problema de las fronteras marítimas mediante la 
conciliación obligatoria prevista en el Convenio de las NACIONES Unidas, el artículo 298 y el anexo $\mathrm{V}$, que Derechos del mar. ${ }^{[15]}$

La dominación de Timor-Leste por otras naciones, en diferentes períodos históricos, la ha perjudicado enormemente. Varias reflexiones sobre la explotación de Indonesia y Australia se sienten en el desarrollo de la gente timorense en varias áreas. Desde 2002, en vísperas de la independencia de Timor-Leste, los australianos se han retirado de varios tratados internacionales para evitar la pérdida de explotación del territorio no marítimo. Los australianos y los timorenses tienen territorios separados por menos de 400 millas náuticas. Debido a la proximidad entre las dos naciones, sus territorios marítimos deben definirse de una manera peculiar y específica, de acuerdo con el principio de equidad. Es esencial profundizar en el conocimiento sobre la ley del mar y el petróleo para entender las razones de hecho y derecho que legitiman la lucha del pueblo timorense por su territorio marítimo. ${ }^{[16]}$

\section{DERECHO DEL MAR Y EL PETRÓLEO}

El Derecho del Mar pertenece al derecho internacional, que observa la soberanía y jurisdicción de los Estados, definiendo el alcance de su dominio marítimo. También regula otros temas como la explotación de los recursos existentes en el lecho y en el fondo marino, además de la preservación y conservación del medio marino. ${ }^{[17]}$ Una de las mayores riquezas que se encuentran en el fondo del mar de Timor es el aceite, que destaca por ser un líquido negro viscoso e inflamable, menos denso que el agua. Consiste en una mezcla de hidrocarburos, moléculas compuestas de átomos de carbono e hidrógeno, así como moléculas de azufre, nitrógeno, oxígeno e iones metálicos, y se encuentra en depósitos subterráneos naturales. ${ }^{[18]}$

La Conferencia de Derechos Marítimos tuvo lugar en Ginebra en 1958. En 1969, fue ratificado por casi todos los países del mundo. Se ocupa de diversos temas o temas que tratan la estrecha conexión en el espacio oceánico entre las naciones. La Convención de las Naciones Unidas sobre los Derechos del Mar (UNCLOS) de 1982 se firmó en Montego Bay, Jamaica, aunque apareció en la conferencia de Ginebra. En este documento se encuentran las normas y principios del mar territorial, las zonas 
${ }^{[19]}$ Contiguas, económicas y continentales. ${ }^{[20]}$ Con respecto a la soberanía del Estado ribereño sobre las aguas adyacentes ${ }^{[21]}$, regula todos los países que la han adoptado, aceptado o ratificado. También existen normas conexas sobre la gestión de los recursos marinos y el control de la contaminación. ${ }^{[22]}$

El PNUD determina que el mar de la costa tiene 12 millas náuticas, es decir, $22 \mathrm{~km}$. En el plano vertical, se extiende hasta el espacio aéreo, tenándolo como límite. El agua de mar de la superficie está limitada por el contacto con el lecho oceánico, el suelo, así como todo el subsuelo se rige por el régimen jurídico marino territorial.. ${ }^{[23]} \mathrm{El}$ derecho del mar a los estados costeros estaba garantizado de explotación económica exclusiva en un aire de 200 millas náuticas, pero esta regla no se aplica a los Estados que están a menos de 400 millas de sus áreas contiguas. ${ }^{[24]}$

Figura 2 - Mar territorial

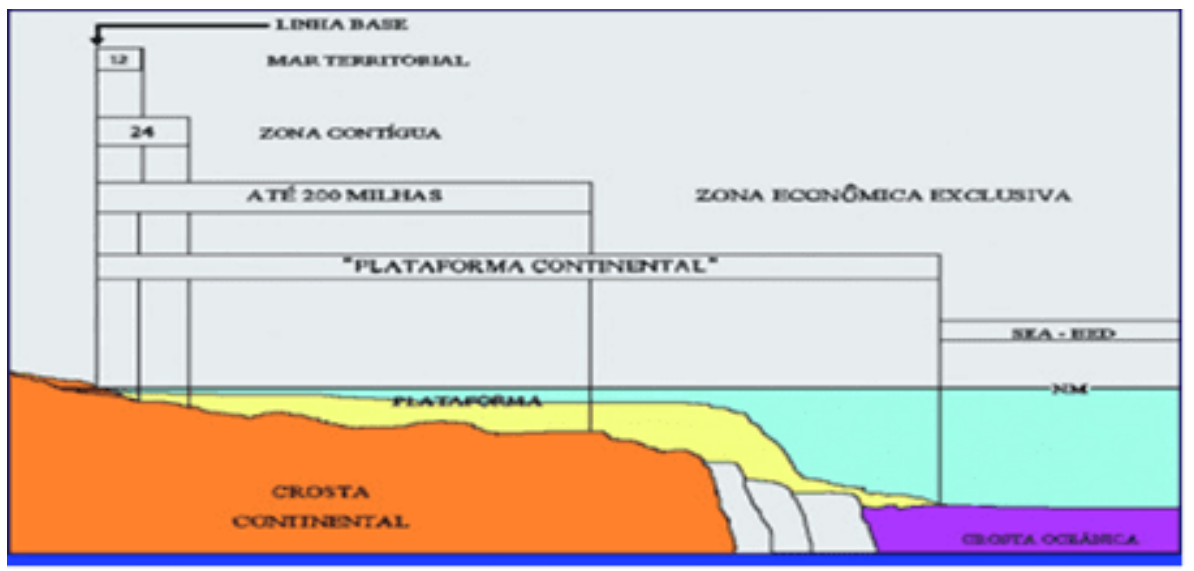

Fuente: GUSM-O (2018).

El Mar Territorial es la zona situada entre las aguas interiores y la Alta Mar. Es la continuación de la soberanía de un país costero que excede su territorio y sus aguas, de acuerdo con los artículos 2 y 3 de la CNULOS. ${ }^{[25]}$ El Estado ejerce soberanía sobre su mar territorial, espacio aéreo, así como el lecho y el subsuelo bajo el mar territorial, según el art. 02 a 32 de la Convención sobre los Derechos del Mar. ${ }^{[26]}$ El límite exterior del mar territorial de cada nación es de veintidós kilómetros. El Estado ejerce su jurisdicción sobre las actividades de interés nacional en la zona marítima contigua, 
que se establece en 12 millas. La Convención de las Naciones Unidas creó la Zona Económica Exclusiva, ZEE, para equilibrar los intereses entre los países. Se trata de una zona situada más allá del Mar Territorial. Se refiere al área cercana a la zona contigua y se extiende hasta 200 millas de la costa. El estado tiene derecho a navegar, volar, instalar cables y conductos marinos, así como a explotar los minerales que se encuentran en el suelo y el subsuelo marino. Timor-Leste y Australia están separados por menos de 400 millas de distancia, y por esta razón esta regla no resuelve los conflictos sobre las fronteras entre las dos naciones. ${ }^{[27]}$

Los timorenses y los australianos son pueblos pertenecientes a estados con costas adyacentes o situadas frente a cara. No cumplen los límites establecidos por la Convención de las Naciones Unidas para la Aplicación de los Derechos del Mar, relacionados con la soberanía del Estado en el mar territorial. La distancia de la costa costera entre los países es de 300 millas. Estos países deben delimitar las fronteras marítimas por acuerdo, según lo determinen las normas del derecho internacional. Las naciones deben lograr una solución justa, justa y equivalente. ${ }^{[28]}$

La Convención de Ginebra tiene criterios para la delimitación paralela. El método de línea mediana se utiliza en circunstancias especiales para estados con respaldos opuestos. Regula un reajuste de la línea mediana entre países. La Convención sobre el Derecho del Mar establece que, habida cuenta de la falta de una distancia de 400 millas para la separación entre dos países, debe utilizarse el principio de equidistancia. [29]

La industria petrolera es extremadamente importante. La sociedad actual depende de ella y de sus derivados. Es un combustible fósil, una fuente de energía eléctrica para la mayoría de los países desarrollados y en desarrollo. Es esencial para la fabricación de una gama de productos como el diésel, el queroseno y la gasolina. También está presente en los insumos y en la industria petroquímica, a través de la parafina y la nafta. Muchos medicamentos tienen en su composición derivados del petróleo. Es imposible reflexionar sobre los moldes actuales de la vida humana sin asfalto, plásticos y aspirina. El aceite se puede observar en los combustibles utilizados para la locomoción de las personas. Está contenido en una multitud de productos químicos 
y petroquímicos fundamentales para el desarrollo de una nación. Debido a su amplia aplicabilidad y debido a que es una fuente agotadora de energía, los australianos han ignorado el derecho del Mar Internacional durante muchos años. Se retiraron del PNUD para evitar que el pueblo timorense tenga derecho a obtener beneficios sobre la explotación de las compañías petroleras Bayu Undan y Greater Sunrise. ${ }^{[30]}$

Debido a la importancia del petróleo, la Organización de Países Exportadores de Petróleo (OPEP) surgió en Viena, Austria, en 1960. Las naciones fundadoras fueron la República Islámica del Irán, Irak, Kuwait, Arabia Saudita y Venezuela. El propósito de Opec es establecer una política común para el petróleo, protegiendo los ingresos de los países productores. Antes de la creación de esta organización, los países exportadores de petróleo que poseían la mayor parte de las reservas de petróleo de la época se beneficiaron poco. Las grandes corporaciones regulan el mercado internacional del petróleo. El valor de los combustibles fósiles pagados a los países productores y para su reventa al consumidor final fue controlado por las compañías petroleras. The American companies Exxon, Texaco, Amoco and Chevro, as well as the Dutch Royal Dutch Shell and British Petroleum were called Seven Sisters. Llevaron a cabo la exploración, refinación, transporte y reventa de petróleo, pero sólo una pequeña parte de los frutos de la extracción estaba destinada a los Estados productores. En la actualidad, las Naciones Unidas también observan las acciones de las empresas petroleras para que pueda producirse un acuerdo adecuado entre los Estados productores y las empresas extractoras de petróleo. ${ }^{[31]}$

Timor-Leste ha sido explorado durante décadas por Australia. Esta conducta fue impulsada sustancialmente por razones económicas, debido al interés en la riqueza del territorio marítimo timorense. No es nuevo que la industria petrolera esté motivada a sacar a Australia de la comunidad internacional. Los australianos no han estado dispuestos a tratar asuntos relacionados con los Derechos del Mar. El interés por los beneficios por la extracción de petróleo y gas natural de la región perteneciente a Timor-Leste impidió llegar a un acuerdo entre las dos naciones durante muchos años. ${ }^{[32]}$ 
Los timorenses han sido perjudicados por Australia desde su independencia en 2002. Todas las reservas de petróleo y gas están en el lado timorense de la línea mediana, es decir, más cerca de Timor-Leste que del territorio australiano. Australia ya no reconoce la jurisdicción de la Corte Internacional de Justicia y de la Convención de las Naciones Unidas sobre el Derecho del Mar para delimitar sus fronteras en la línea media con Timor-Leste meses antes de su independencia. La expulsión de Australia del PNUD tenía la intención de evitar la pérdida o reducción del espacio territorial marítimo, ya que pertenecía al derecho a los timorenses. La Convención de las Naciones Unidas sobre los Derechos del Mar establece que cada país debe delimitarse como una zona económica exclusiva a 200 millas náuticas, del límite exterior de su mar territorial, a 12 millas de la costa. EI PNUD también se ocupa de las grandes profundidades del mar que se conocen como zona o zona $A$, según el arte. 1. Esta zona se compone de fondos marinos y oceánicos y su subsuelo. ${ }^{[33]}$

Figura 3 - Línea de demarcación fronteriza de Australia

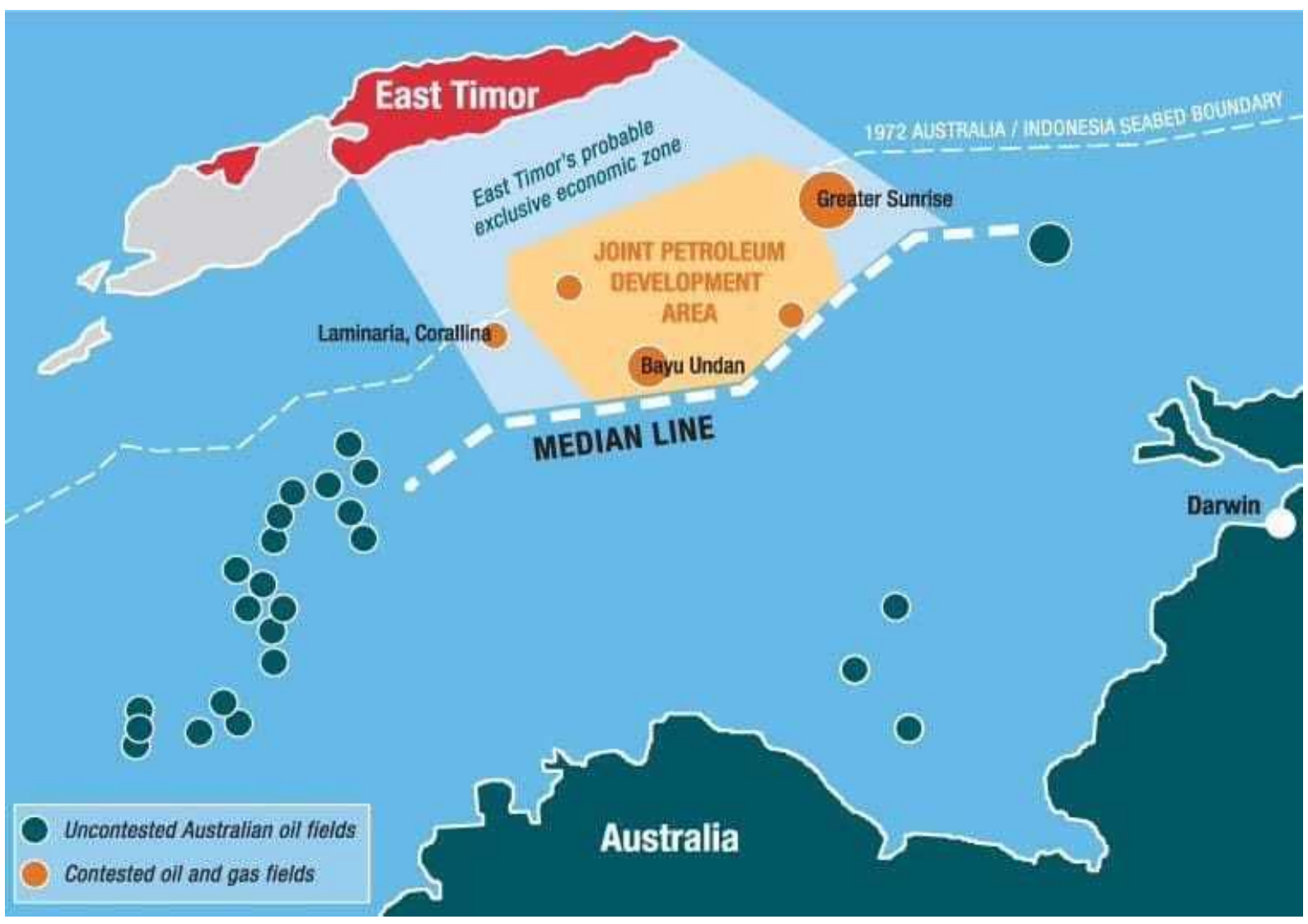

Fuente: TIMOR SEA JUSTICE (2016). [34] 
Los principios contenidos en la Convención de las Naciones Unidas sobre los Derechos del Mar establecen que la frontera marítima entre los dos países involucrados debe definirse por la línea equidistante, es decir, la línea mediana. La demarcación de las fronteras entre Australia y Timor-Leste a través del principio de equidistancia incluye territorio timorense con toda la zona de exploración del pozo de la petrolera Bayu Undan. El campo petrolero Greater Sunrise se encuentra en la llamada Zona de Cooperación y, según la UnCLOS, este territorio también pertenece al pueblo timorense. ${ }^{[35]}$

El petróleo es una riqueza que reside en abundancia en Timor-Leste. La línea mediada debe trazarse para definir el espacio marítimo entre dos países que seseparan por menos de 400 millas náuticas. Las empresas australianas en Timor-Leste encontraron yacimientos de gas natural y petróleo antes de su independencia. Por esta razón, los australianos han tenido mucha resistencia a un tratado definitivo sobre el derecho a la explotación del mar de Timor. Las dificultades a las que se enfrentan estas personas para obtener sus derechos marítimos son cuestiones importantes. El análisis de los detalles que precedieron al tratado definitivo llevado a cabo en 2018, que se ocupa de las fronteras timorenses, es esencial para comprender la proporción de acontecimientos que significa este pacto. [36]

\section{TRATAMIENTO ENTRE AUSTRALIA Y TIMOR-LESTE}

En 2002, Timor-Leste obtuvo su independencia de Indonesia, pero desde ese año, las fronteras marítimas definitivas de Timore no han sido demarcadas. Los australianos, durante muchos años, no tienen interés en tratar las fronteras marítimas de timorleste, respetando las normas de derecho internacional. Tenían la intención de seguir utilizando los recursos del mar que no les pertenecían. Aunque causaron daños al desarrollo de Timor-Leste en varias zonas durante mucho tiempo, el pacto no ha previsto la indemnización de los daños causados desde 2002. [37]

El pueblo timorense no será reembolsado por los daños causados a su evolución en las áreas de educación, social, económica, política, entre otros que requieren recursos financieros mínimos para ocurrir. Pero cuando se llevó a cabo el pacto, se observó 
que Timor-Leste ha sido muy perjudicado a lo largo de los años por Australia. ${ }^{[38]}$ Con el fin de fomentar el desarrollo, la industria, la tecnología y la economía de los timoreses, se acordó que la empresa que llevaría a cabo la exploración del Gran Amanecer tendría que contratar a los ciudadanos de Timor-Leste, facilitándoles la formación fomentando el desarrollo de sus estudios, así como tendría el deber de adoptar el país como la primera opción para la adquisición de bienes y servicios. ${ }^{[39]}$

Con el fin de evitar pérdidas económicas, Australia se retiró de varios Tratados Internacionales de los que fue parte integrante meses antes de la independencia de Timor-Leste. ${ }^{[40]}$ Con el fin de evitar que cualquiera de los dos países no haya observado el pacto en el futuro, las naciones estipularon que el tratado no estaría sujeto a un derecho unilateral a la denuncia, retirada o suspensión. En el texto del documento se aclaró que todas las cláusulas expresadas en el tratado y los anexos forman parte del pacto y no pueden ser ignoradas ni resaltadas. Ante una posible disputa futura, se acordó que podría resolverse con la ayuda de los miembros de la Comisión de Conciliación que mediaron el pacto entre las dos naciones en 2018. Sin embargo, en la permanencia del desacuerdo sobre las cuestiones, las cuestiones abordadas con la intervención de los miembros del Comité de Conciliación podrían ser presentadas ante el tribunal arbitral, y esa segunda decisión tendría un efecto vinculante. ${ }^{[41]}$

El 6 de marzo de 2018 tuvo lugar el acuerdo entre Timor-Leste y Australia. Este pacto delimita la cuenca continental. En este documento, la línea mediana y las fronteras laterales fueron demarcadas al este y al oeste de la zona antigua conocida como Timor Gap, según el arte. 10 del tratado fronterizo marítimo de Timor-leste. ${ }^{[42]} \mathrm{A}$ partir de este nuevo contexto, Timor-Leste se permite llevar a cabo la explotación de los recursos del suelo marino, como el petróleo y el gas natural, además de proporcionar los beneficios a los derechos de la zona económica exclusiva. Esta nación también se ganó el derecho de explotar otros recursos marítimos como la pesca, lo que permitió un aumento de los recursos financieros para el país. ${ }^{[43]}$ 
Figura 4 - Tratado de Australia y Timor-Leste sobre las fronteras de Timor

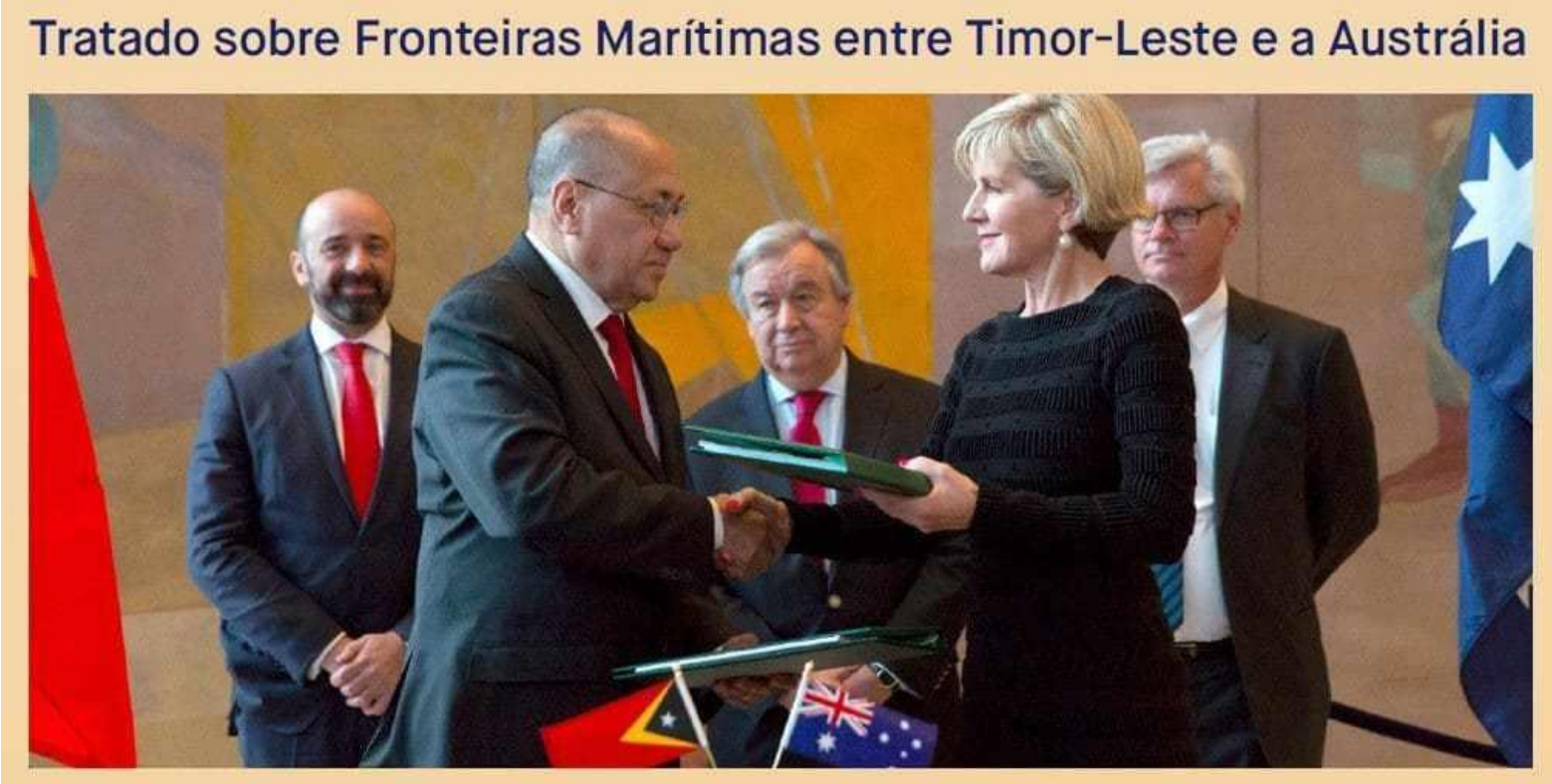

Fuente: Timor-Leste (AUSTRALIA, 2018)[44]

. Timor-Leste y Australia relajaron sus intereses para resolver los desacuerdos que les impidieron llegar a un acuerdo. En la zona territorial marítima donde se encuentra el Gran Amanecer, se acordó que pertenecería a cada uno de los países implicados en el acuerdo a la mitad de los resultados de la operación de esa región territorial marítima. Los campamentos Bayu-Undan, Buffalo y Kitan están totalmente integrados en territorio titisado. ${ }^{[45]}$

No se definieron las formas en que se repartirían los ingresos entre Timor-Leste y Australia, ya que dependerían de varios factores. Cuanto mayor sea la capacidad de desarrollar técnicas y aplicarlas, mayores serán sus beneficios. De acuerdo con las formas de explorar los campos del Gran Amanecer, los resultados se compartirían. En el año en que se produjo el pacto, se acordó que los ingresos por los campos petroleros pertenecerían al 30 por ciento a Australia y al 70 por ciento a Timor-Leste si se aumentaba la exploración mediante el desarrollo del gasoducto para el pueblo timorense. También se predijo que, en el caso de que los campos del Gran Amanecer se desarrollaran a través de un Pipeline to Australia, los porcentajes serían 
modificados, pertenecientes al $20 \%$ para los australianos y al $80 \%$ para los timorenses. ${ }^{[46]}$

En el tratado definitivo sobre fronteras, según el arte. 12 del documento jurídico, se definió que la exploración de gas y petróleo en la región de campo del Gran Amanecer dependería de la definición entre las partes del plan de desarrollo. Resulta que después del inicio de las actividades de exploración de la región marítima que habrían compartido ingresos, la empresa contratada se sometería a la jurisdicción exclusiva del país donde se encuentra. Se establecería el Consejo de Supervisión de dos representantes de Timor-Leste y un representante de Australia. Con el fin de encontrar soluciones a los litigios, habría un Comité Independiente de Resolución de Conflictos para las decisiones sobre las estrategias adoptadas para la exploración del campo petrolero mencionado anteriormente. ${ }^{[47]}$

Durante décadas, Australia ha demostrado su intención de obtener beneficios de la explotación de los yacimientos petrolíferos en su totalidad. Se necesitaba una intervención internacional para reducir el conflicto sobre las fronteras entre timorenses y australianos. El Tratado definitivo sobre fronteras se refiere a la mediana de la línea y los límites laterales en el territorio de Timor-Leste y comparte los ingresos de una región petrolera entre los países involucrados. Pero este pacto no extingue la posibilidad de futuros conflictos sobre los beneficios de los campos del Gran Amanecer. Había muchas preguntas pendientes de aclaración, que exigían que surgieran conflictos concretos para que se adoptaran las posiciones. Ante esta nueva situación, el pueblo timorense se enfrentará a varios obstáculos para que puedan disfrutar de todas las posibilidades para su desarrollo en diversas áreas. ${ }^{[48]}$

\section{LOS OBSTACLEOS AL DESARROLLO DE TIMOR-LESTE}

Timor-Leste es un estado marítimo y no sólo petróleo. Hay varios sectores que pueden contribuir a la evolución de la nación. Durante muchos años fue explorado por Portugal, Indonesia y Australia. Se han invertido pocos recursos en educación e infraestructura. La nación ha sido perjudicada en el desarrollo de varias áreas debido al abandono de Indonesia. Hay pocos profesionales con habilidades técnicas, 
políticas, legales y administrativas, porque durante el período de dominación de la gente, sólo se contrató a profesionales extranjeros para realizar actividades en estas áreas. ${ }^{[49]}$

Figura 5 - Estudiantes de una escuela en la periferia timorense

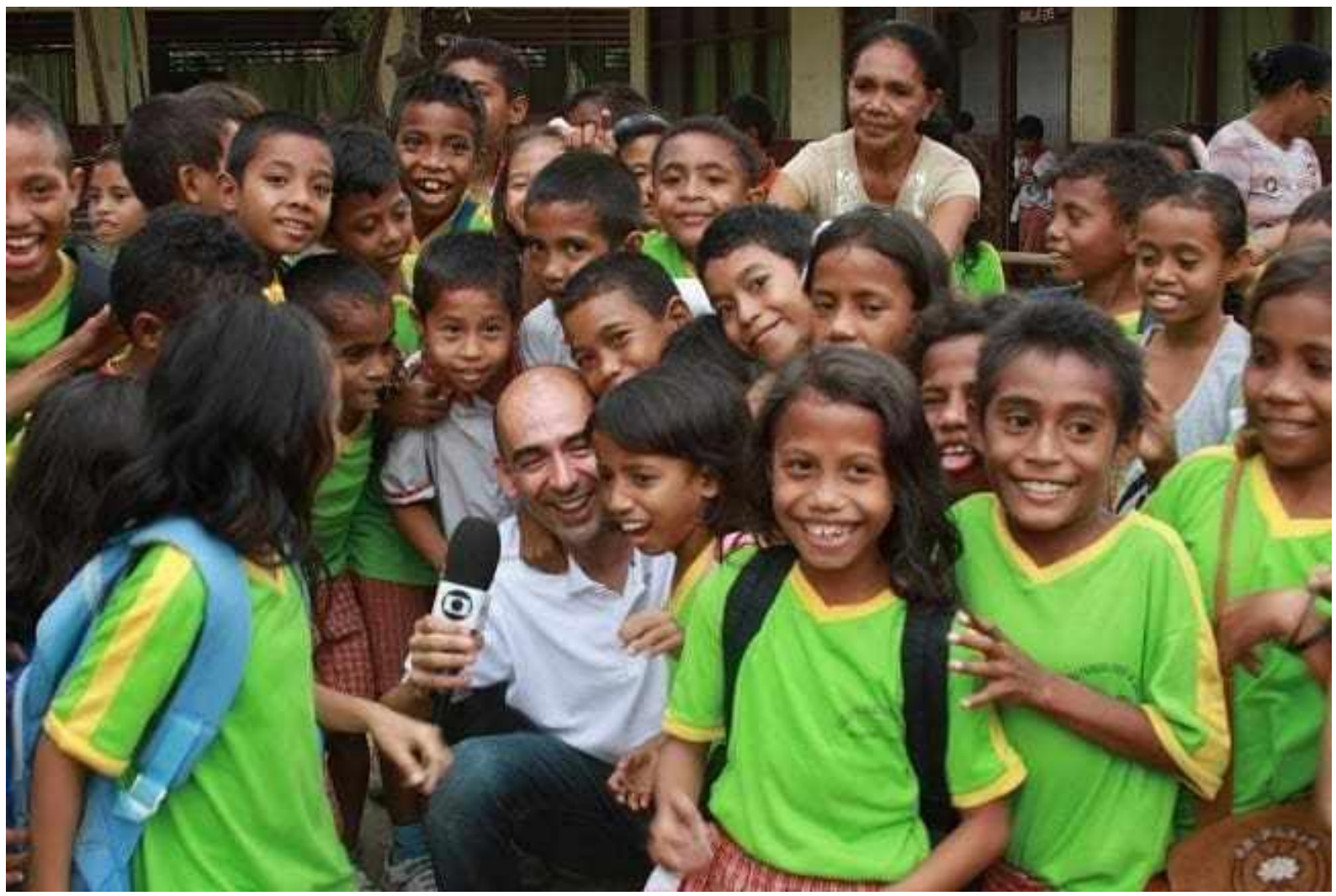

Fuente: Partners for Peace (2011).[50]

Desde 2011, Timor-Leste cuenta con un plan estratégico de desarrollo que incluye la evolución del capital humano, la infraestructura, la economía, la política y el área administrativa. El objetivo del gobierno timorense es alcanzar los objetivos establecidos en el plan de desarrollo para 2030. Los recursos procedentes de los derechos de explotación de su territorio marítimo aportarán mayor celeridad en la aplicación de los objetivos propuestos en el plan de desarrollo timorense. El pacto de Australia sobre fronteras definitivas sin duda generará varias situaciones peculiares y sin precedentes. El conocimiento específico sobre los métodos de exploración de petróleo y gas natural será esencial para entender qué alternativas traerán más beneficios al país. Después de la ratificación del tratado, se establecieron muchas 
normas para que los timorenses pudieran disfrutar de sus derechos, pero necesitarán profesionales cualificados en diversas esferas. Y uno de los principales desafíos a los que se enfrenta Timor-Leste es la corta experiencia en la administración pública, con grandes volúmenes de ingresos financieros, que se multiplicarán debido al tratado definitivo en sus fronteras. ${ }^{[51]}$

En el documento del tratado se establecieron normas que involucraban a grandes empresas exploradoras internacionales. Las compañías petroleras deben contribuir al desarrollo de timor-leste mediante la contratación preferente de profesionales, servicios y productos en el país. Timorese no sólo se relacionará con representantes del gobierno australiano, sino con una resuma de iniciativa privada con experiencia. Los representantes extranjeros del gobierno australiano o empresas privadas de varias naciones pueden tener una vasta capacidad para negociar y tratar con timorenses inexpertos. Timor-Leste tiene profesionales con poca habilidad técnica, pero esta situación no debe comprometer el desarrollo. La misión de estos empresarios será ayudar en la educación y enseñanza de las habilidades y conocimientos requeridos por los trabajadores para realizar tareas relacionadas con las actividades de exploración. El aumento de los recursos financieros contribuirá a la transformación de los sectores, técnicos, administrativos, políticos, legales, entre otros, facilitando la transposición de obstáculos al desarrollo de la nación. ${ }^{[52]}$

La exploración del gas y el petróleo requerirá que el poder legislativo de Timor-Leste sea consciente de la aparición de nuevos hechos derivados de esta actividad. Las agencias estatales tendrán que encontrar respuestas rápidas a las divergencias entre el Estado, los representantes de las empresas explotadoras y Australia. Aunque la empresa contratada tiene la obligación de someterse a la jurisdicción exclusiva del país donde se encuentra, debe considerarse la experiencia y la capacidad de los representantes del sector privado para manipular las negociaciones. Es innegable que el Gobierno de Timor-Leste adopta posiciones que contribuyen al progreso en diversas zonas del país, pero es un hecho que los más timoreses poderes ejecutivos, legislativos y judiciales todavía se están desarrollando, porque es un país muy joven. ${ }^{[53]}$ 
Timor-Leste tiene una amplia experiencia en los combates, ya que el pueblo se organizó contra la invasión de Indonesia y obtuvo su independencia. ${ }^{[54]}$ Actualmente, avanza en la búsqueda de proporcionar educación, infraestructura, economía, política y gestión administrativa adecuada para los ciudadanos. En el pacto sobre fronteras definitivas, se reconoció la situación fragilidad de Timor-Leste. Y los mecanismos para ayudar en la evolución del país fueron positivos en el acuerdo. ${ }^{[55]}$

El Gobierno de Timor-Leste tendrá tareas complejas y será necesario un sector jurídico y administrativo preparado para actuar en nuevas actividades. Los informes y planes de desarrollo sobre la exploración de los campos Bayu-Undan, Buffalo y Kitan tendrán que ser emitidos durante el período de transición de exploración de esa región. Este deber requerirá conocimientos técnicos específicos sobre la exploración de petróleo y gas. ${ }^{[56]}$ Muchos sectores están relacionados con el desarrollo de una nación. Las políticas de inversión en sectores que tienen fuentes renovables de explotación deben ser observadas por el Gobierno de Timor-Leste. Deben tenerse en cuenta las disposiciones del Pacto sobre las fronteras timorenses, relacionadas con el deber de las empresas de ayudar en la evolución de diversos sectores. El Estado tendrá que esforzarse por el desarrollo en la misma medida en que debería exigir una iniciativa privada para contribuir a la evolución del país. ${ }^{[57]}$

El crecimiento económico es fundamental para el progreso en infraestructura, política y administración. El ascenso económico de Timor-Leste está vinculado a los sectores de la agricultura, el turismo y el mar, y no sólo a la exploración del petróleo y el gas. La agricultura es esencial para Timor-Leste, así como tiene gran relevancia para otras naciones. De ella se produce comida. Los productos primarios de la agricultura pueden ser utilizados por las industrias, el comercio y el sector de los servicios. Pueden convertirse en la base para mantener la economía nacional e internacional. ${ }^{[58]}$

La exploración de la economía marítima también es crucial para la evolución de la nación timorense. Muchas personas dependen del mar y se apoyan con los recursos generados por la pesca y la recolección de especies marinas. Resulta que, en el territorio marítimo de ese país, hay un paso natural de peces. $Y$ a través de los acontecimientos provocados por el pacto definitivo sobre las fronteras, varias especies 
de peces podrían ser explotadas por las industrias nacionales. Además del aumento de los ingresos para el surgimiento de industrias interesadas en las muchas especies de escuelas que tiene esa región, esta nación se encuentra en el Triángulo de Coral. Este es un patrimonio cultural que puede ser apreciado por el turismo, así como puede servir como un interés para la investigación científica. Las características anteriores pueden generar el aumento directo e indirecto de los recursos para el Estado, siempre que se produzcan las medidas administrativas apropiadas. ${ }^{[59]}$

La infraestructura de los puertos y aeropuertos de Timor también es fundamental para el crecimiento del país. Los parámetros de las construcciones estratégicas deben monitorear las necesidades de las navegaciones del escenario global que el territorio timorense puede transitar a través del territorio timorense. Los puertos de Dili, Oecusse, Hera, Caravela y Com tienen actualmente características inadecuadas, lo que requiere que las inversiones sean consideradas como centros industriales. Esta evolución creará oportunidades para que Timor-Leste se convierta en un tránsito de carga petrolera, así como para convertirla en una nación que posea un gran centro industrial que conecte los océanos Pacífico e Indico. ${ }^{[60]}$

Timor-Leste debe seguir avanzando en muchas áreas. Los sectores agrícola, petrolero, marítimo, turístico, educativo, jurídico, político y económico necesitan transformaciones. Ya existe un plan de política de desarrollo que se creó en 2011. Sin embargo, es necesario adaptarlo a la nueva realidad en la que se encuentra el país, tras los cambios que se produjeron por la definición de sus fronteras marítimas finales. ${ }^{\left[{ }^{[1]}\right.}$ Las estrategias específicas para cada sector deberán repasarse a nivel nacional interno. Y, sobre la base de estos nuevos objetivos, deben adoptarse las posiciones con las empresas de exploración de petróleo y gas, del mismo lado que todas las decisiones del Estado para alcanzar estos objetivos de crecimiento. [62]

\section{CONCLUSIÓN}

Timor-Leste se encuentra en el sudeste asiático y es un país muy joven, que obtuvo su independencia en 2002. Es el vecino de la indonesia, que se encuentra al norte, y al sur es Australia. Tiene una nación caracterizada por su fuerza y lucha. Este guerrero 
y las personas que sufren se comunican a través de la lengua portuguesa y Tetum, oficialmente, pero en el territorio hay más de 14 lenguas nativas. Fue colonizado por Portugal e invadido por Indonesia en 1975. Tiene un tesoro situado en su territorio marítimo, debido al petróleo y gas natural que en el mar de Timor se encuentran. Estas riquezas de Timor-Leste fueron objeto de una batalla con Australia. El desacuerdo entre los australianos y los timorenses comenzó meses antes de la independencia de Timor-Leste de Indonesia. Australia no tenía ningún interés en negociar, como prevé el derecho internacional del mar, para evitar la pérdida de ingresos procedentes del mar de Timor. Pero en 2018, se celebró un Tratado Definitivo sobre las fronteras de Timor-Leste con los australianos. Este fue el momento histórico en el que la nación obtuvo el reconocimiento del derecho a disfrutar de su mar territorial.

La delicada situación económica del país fue reconocida en el Tratado fronterizo definitivo de Timor-Leste. La escasez de recursos económicos está relacionada con la explotación de esta nación de una manera devastadora. Portugal invirtió poco durante el período de más de 400 años en el que este país era su colonia. Después de ser liberado de la dominación portuguesa, tuvo lugar un nuevo ataque a TimorLeste. Durante más de veinticuatro años, los morenos sufrieron la ocupación de Indonesia, pero se realizaron pequeñas inversiones. Sin embargo, a partir del período en que el pueblo timorense mostró interés en luchar por su independencia, todo fue destruido por el pueblo indonesio. En la fase inicial de la ocupación de Timor-Leste por Indonesia, la comunidad internacional contribuyó con ayuda a la reconstrucción básica del país.

La independencia de los timorenses no les dio el derecho inmediato de tomar posesión de la riqueza marítima que les pertenecía, debido al hecho de que estaban en su territorio. Los acuerdos provisionales sobre fronteras, los pactos que perjudicaron a los timorenses se celebraron con Australia antes de 2018. Desde 2002, Timor-Leste ha reclamado la propiedad de su territorio marítimo, según lo dispuesto en las normas de derecho internacional, UNCLOS/1982. Resulta que unos meses antes de que Timor-Leste obtuviera su independencia, Australia se retiró de varios pactos internacionales. 
Dado que los territorios marítimos de Timor-Leste y Australia se separaron por una distancia inferior a 400 millas náuticas, a poca distancia entre los territorios de las dos naciones, la línea de delimitación fronteriza adoptada se definió por el estándar de equidistancia y línea mediana. Este es el modelo previsto en la Convención de las Naciones Unidas sobre los Derechos del Mar de 1982, utilizada para resolver conflictos que han sido sobre territorios que se distancian por menos de 400 millas náuticas.

Los australianos han evitado llegar a un acuerdo con los timorenses en las fronteras definitivas, de conformidad con las normas de la Convención de las Naciones Unidas sobre los Derechos del Mar durante muchos años. El objetivo de esta postura era irrespetar la forma de delimitar las fronteras marítimas, lo que establece de manera estándar la adopción de la línea mediana y la equidistancia en conflictos específicos sobre la definición de las fronteras. La razón de la expulsión de Australia de la comunidad internacional está relacionada con la extensión del beneficio de la explotación del mar que pertenece al pueblo timorense.

Después de varios intentos de llegar definitivamente a un acuerdo sobre las fronteras timorenses con Australia, el país tuvo éxito. Clara y específicamente, en un documento que tiene más de 11 artículos, las fronteras marítimas bilaterales permanentes se abordaron a lo largo de una línea esencialmente equidistante entre las dos naciones. Timor-Leste delimitaba sus fronteras según lo dispuesto en la Convención de las Naciones Unidas sobre el Derecho del Mar. En el tratado se acordó que existe un vínculo indivisible entre la frontera marítima de Timor-Leste y Australia. Se resumió la existencia de una zona marítima perteneciente a las dos naciones involucradas en el pacto.

Durante la preparación del documento, las partes compartieron los ingresos procedentes de la explotación de mayores campos de salida del sol y positivos en el texto del pacto internacional la necesidad de elaborar normas relativas a la explotación de los campos de la región pertenecientes a los dos Países. Se ha establecido que las normas acordadas en el Tratado o en sus anexos no pueden ser parcialmente desatendidas por ninguna de las partes implicadas. También se reguló que es 
necesario crear planes de exploración de la riqueza marina antes de que comiencen los procedimientos, así como también se acordó que las compañías petroleras tendrían que comprar productos y servicios preferiblemente del pueblo timorense.

El pacto fronterizo definitivo de Timor-Leste no es sólo un acuerdo común entre los gobiernos de dos naciones. Este pacto timorense y australiano también abarca las obligaciones de iniciativa privada. Se han asignado derechos a empresas que llevarán a cabo la exploración de petróleo y gas en la región de los campos del Gran Amanecer. Deberían contribuir al desarrollo de Timor-Leste.

Es necesario eliminar muchos obstáculos para que Timor-Leste pueda desarrollarse ampliamente, a pesar de haber ganado el derecho a explorar su territorio marítimo. El petróleo y el gas son recursos no renovables, es decir, son fuentes de ingresos con una terminación estimada. Pero son fuentes de ingresos inmediatos y rentables. El desarrollo de la educación, la infraestructura, la agricultura, el turismo y la prestación de servicios es esencial para construir una base de ingresos sólida y renovable a medio y largo plazo. El país se enfrenta a varios obstáculos, como la poca infraestructura y el bajo nivel de educación, pero ha estado creciendo mucho desde 2002.

En un mundo capitalista, es innegable que los recursos financieros son factores determinantes para la amplia evolución de una nación. El aumento de los ingresos procedentes de la exploración del petróleo y el gas aumentará los ingresos financieros, hecho que contribuirá a la evolución de la educación y a las inversiones en la infraestructura de los puertos y aeropuertos de Timor-Leste. Si, antes del Tratado sobre fronteras definitivas, la educación, la infraestructura, la agricultura y la pesca industrial eran obstáculos para el desarrollo de los timorenses, se espera que, después del pacto definitivo con Australia, se modifique esta realidad.

\section{REFERENCIAS}

BRASIL. Decreto no 99.165, de 12 de março de 1990. Convenção das Nações Unidas sobre o Direito do Mar. Brasília: Planalto, 1990. Disponível em: 
https://www2.camara.leg.br/legin/fed/decret/1990/decreto-99165-12-marco-1990328535-publicacaooriginal-1-pe.html. Acesso em 15 abr.19.

DEL'OMO, Florisbal de Souza. Curso de direito internacional público. Rio de Janeiro: Forense, 2006.

GIBERTONI, Carla Adriana Comitre. Teoria e prática do direito marítimo. Rio de Janeiro: Renovar, 1998.

GOMES, Danaciano. Timor Leste: A economia do mar: um contributo para desenvolvimento sustentável. Aveiro: Mare Liberum, 2016.

GUSMÃO, Kay Raia Xanana. Breve história do mar do Timor. In: GOVERNO DO ESTADO DO TIMOR LESTE. Novas Fronteiras: conciliação histórica das fronteiras marítimas no mar do timor. Dili: Gabinete das Fronteiras marítimas, 2018.

MARCONI, Maria de Andrade, Lakatos, Eva, Maria. Fundamentos da metodologia cientifica. São Paulo: Atlas. 2003.

MARITIME BOUNDARY OFFICE. New frontiers: Timor-Leste's historic conciliation on maritime boundaries in the timor sea. [S. I.], 2015. Disponível em: http://www.gfm.tl/wp-content/uploads/2015/11/Website-map-of-Timor-Sea.pdf. Acesso em: 04 maio 2019.

MATTOS, Adherbal. Meira. O novo direito do mar. Rio de Janeiro: Renovar. 1996.

PEREIRA, Eliana Sofia da Silva. Contributo crítico para a compreensão do regime do Mar de Timor à luz do Direito Internacional. 2013. 87 f. Dissertação. (Mestrado em Ciências Jurídicas Internacionais) Faculdade de direito- Universidade Nova de Lisboa, 2013. p.14. Disponível em: https://run.unl.pt/bitstream/10362/17481/1/Pereira_2013.pdf. Acesso em: 01 abr. 2019.

REPÚBLICA DEMOCRÁTICA DE TIMOR-LESTE. Ministério das finanças. Orçamento geral do Estado 2018. Díli: Gabinete Ministerial, 2018. p. 7. Disponível 
em: https://www.mof.gov.tl/wp-content/uploads/2018/08/BB5_Port.pdf. Acesso em: 15 maio 2019.

REPUBLICA DEMOCRÁTICA DO TIMOR LESTE. História do Timor Leste. Governo do Timor Leste, Dili, [s. d.]. Disponível em: http://timor-leste.gov.tl/?p=29\&lang=pt. acesso em: 05 maio 2019.

REZEK, José Francisco. Direito internacional público: curso elementar. 10. ed. rev. e atual. São Paulo: Saraiva, 2005.

RIBEIRO, Marilda, Rosado de Sá. Direito do petróleo. 3. ed. rev. atual. e ampl. Rio de Janeiro: Renovar, 2018.

TIMOR LESTE; AUSTRÁLIA. Tratado sobre fronteiras marítimas entre Timor Leste e Austrália que estabelece as respectivas fronteiras do mar do Timor Leste. Nova York: [s.n.], 2018. p. 1. Disponível em: http://www.gfm.tl/wpcontent/uploads/2018/03/Port-Timos-Sea-Maritime-Boundary-

Treaty_Portuguese.pdf. Acesso em:04 maio 2018.

TIMOR SEA JUSTICE. All of the contested oil \& gas fields are on EastTimor's side of the median line ie closer to \#Timor than Australia. Dili, 01 mar. 2016. Tiwitte: @timor sea justice. Disponível em: https://twitter.com/TimorSeaJustice/status/704895304701763584. Acesso em: 25 maio. 2019.

ZANELLA, T. V. Curso de direito do mar. Curitiba: Juruá, 2013.

\section{APÊNDICE - REFERENCIAS DE NOTA DE RODAPÉ}

3. GOMES, Danaciano. Timor-Leste: A economia do mar: um contributo para desenvolvimento sustentável. Aveiro: Mare Liberum, 2016. 
4. GUSMÃO, Kay Raia Xanana. Breve história do mar do Timor. In: GOVERNO DO ESTADO DO TIMOR LESTE. Novas Fronteiras: conciliação histórica das fronteiras marítimas no mar do timor. Dili: Gabinete das Fronteiras marítimas, 2018. p. 6.

5. RIBEIRO, Marilda, Rosado de Sá. Direito do Petróleo. 3. ed. rev. atual. e ampl. Rio de Janeiro: Renovar, 2018.

6. RIBEIRO, Marilda, Rosado de Sá. Direito do Petróleo. 3. ed. rev. atual e ampl. Rio de Janeiro Renovar, 2018.

7. GOMES, Danaciano. Timor Leste: a economia do mar: um contributo para desenvolvimento sustentável. Aveiro: Mare Liberum, 2016.

8. MARCONI, Maria de Andrade, Lakatos, Eva, Maria. Fundamentos da metodologia cientifica. São Paulo: Atlas. 2003.

9. GUSMÃO, Kay Raia Xanana. Breve história do mar do Timor. In: GOVERNO DO ESTADO DO TIMOR LESTE. Novas Fronteiras: conciliação histórica das fronteiras marítimas no mar do timor. Dili: Gabinete das Fronteiras marítimas, 2018. p. 7-8.

10. MARITIME BOUNDARY OFFICE. New frontiers: Timor-Leste's historic conciliation on maritime boundaries in the timor sea. [S. I.], 2015. Disponível em: http://www.gfm.tl/wp-content/uploads/2015/11/Website-map-of-Timor-Sea.pdf. Acesso em: 04 maio 2019.

11. GOMES, Danaciano. Timor Leste: A economia do mar: um contributo para desenvolvimento sustentável. Aveiro: Mare Liberum, 2016. p. 35-36.

12. GOMES, Danaciano. Timor Leste: A economia do mar: um contributo para desenvolvimento sustentável. Aveiro: Mare Liberum, 2016. p. 37 e 38

13. PEREIRA, Eliana Sofia da Silva. Contributo crítico para a compreensão do regime do Mar de Timor à luz do Direito Internacional. 2013. 87 f. Dissertação. (Mestrado em Ciências Jurídicas Internacionais) Faculdade de direito- Universidade Nova de Lisboa, 2013. p.14. Disponível em: 
https://run.unl.pt/bitstream/10362/17481/1/Pereira_2013.pdf. Acesso em: $01 \mathrm{abr}$. 2019.

14. PEREIRA, Eliana Sofia da Silva. Contributo crítico para a compreensão do regime do Mar de Timor à luz do Direito Internacional. 2013. 87 f. Dissertação. (Mestrado em Ciências Jurídicas Internacionais) Faculdade de direito- Universidade Nova de Lisboa, 2013. p.14. Disponível em: https://run.unl.pt/bitstream/10362/17481/1/Pereira_2013.pdf. Acesso em: 01 abr. 2019.

15. TIMOR LESTE; AUSTRÁLIA. Tratado sobre Fronteiras Marítimas entre Timor Leste e Austrália que estabelece as respectivas fronteiras do mar do Timor Leste. Nova York: [s.n.], 2018. p. 1. Disponível em: http://www.gfm.tl/wpcontent/uploads/2018/03/Port-Timos-Sea-Maritime-BoundaryTreaty_Portuguese.pdf. Acesso em:04 maio 2018.

16. PEREIRA, Eliana Sofia da Silva. Contributo crítico para a compreensão do regime do Mar de Timor à luz do Direito Internacional. 2013. 87 f. Dissertação. (Mestrado em Ciências Jurídicas Internacionais) Faculdade de direito- Universidade Nova de Lisboa, 2013. p.14. Disponível em: https://run.unl.pt/bitstream/10362/17481/1/Pereira_2013.pdf. Acesso em: 01 abr. 2019.

17. MATTOS, Adherbal. Meira. O novo Direito do Mar. Rio de Janeiro: Renovar. 1996. p. 04

18. RIBEIRO, Marilda, Rosado de Sá. Direito do Petróleo. 3. ed. rev. atual. e ampl. Rio de Janeiro: Renovar, 2018.

19. Zona Contígua é Faixa entre o mar territorial e o alto-mar, fixada entre 12 e 24 milhas, na qual o Estado exerce sua jurisdição sobre atividades marítimas e sobre diversos interesses nacionais. 
20. Plataforma continental é definida como uma faixa de terra submersa, em toda a extensão do litoral do continente. Geralmente, a plataforma possui uma extensão de 70 a 90 km, e profundidade de 200 metros, até atingir as bacias oceânicas.

21. Nota explicativa: Águas adjacentes são aquelas que banham as margens do território de uma nação.

22. ZANELLA, T. V. Curso de Direito do Mar. Curitiba: Juruá, 2013.

23. ZANELLA, T. V. Curso de Direito do Mar. Curitiba: Juruá, 2013.

24. RIBEIRO, Marilda, Rosado de Sá. Direito do Petróleo. 3. ed. rev. atual. e ampl. Rio de Janeiro: Renovar, 2018.

25. REZEK, José Francisco. Direito Internacional Público: curso elementar. 10. ed. rev. e atual. São Paulo: Saraiva, 2005. p.307

26. BRASIL. Decreto no 99.165, de 12 de março de 1990. Convenção das Nações Unidas sobre o Direito do Mar. Brasília: Planalto, 1990. Disponível em: https://www2.camara.leg.br/legin/fed/decret/1990/decreto-99165-12-marco-1990328535-publicacaooriginal-1-pe.html. Acesso em 15 abr.19.

27. GIBERTONI, Carla Adriana Comitre. Teoria e prática do direito marítimo. Rio de Janeiro: Renovar, 1998. p.33.

28. GOMES, Danaciano. Timor Leste: A economia do mar: um contributo para desenvolvimento sustentável. Aveiro: Mare Liberum, 2016. p.51

29. PEREIRA, Eliana Sofia da Silva. Contributo crítico para a compreensão do regime do Mar de Timor à luz do Direito Internacional. 2013. 87 f. Dissertação. (Mestrado em Ciências Jurídicas Internacionais) Faculdade de direito- Universidade Nova de Lisboa, 2013. p.56. Disponível em: https://run.unl.pt/bitstream/10362/17481/1/Pereira_2013.pdf. Acesso em: 01 abr. 2019. 
30. GOMES, Danaciano. Timor Leste: A economia do mar: um contributo para desenvolvimento sustentável. Aveiro: Mare Liberum, 2016. p.110 e 111

31. RIBEIRO, Marilda, Rosado de Sá. Direito do Petróleo. 3. ed. rev. atual. e ampl. Rio de Janeiro: Renovar, 2018. P. 74 à 80

32. GUSMÃO, Kay Raia Xanana. Breve história do mar do Timor. In: GOVERNO DO ESTADO DO TIMOR LESTE. Novas Fronteiras: conciliação histórica das fronteiras marítimas no mar do timor. Dili: Gabinete das Fronteiras marítimas, 2018.

33. DEL'OMO, Florisbal de Souza. Curso de Direito Internacional Público. Rio de Janeiro: Forense, 2006. p. 292.

34. TIMOR SEA JUSTICE. All of the contested oil \& gas fields are on EastTimor's side of the median line ie closer to \#Timor than Australia. Dili, 01 mar. 2016. Tiwitte: @timor sea justice. Disponível em: https://twitter.com/TimorSeaJustice/status/704895304701763584. Acesso em: 25 maio. 2019.

35. GUSMÃO, Kay Raia Xanana. Breve história do mar do Timor. In: GOVERNO DO ESTADO DO TIMOR LESTE. Novas Fronteiras: conciliação histórica das fronteiras marítimas no mar do timor. Dili: Gabinete das Fronteiras marítimas, 2018. p. 34 e 35

36. DEL'OMO, Florisbal de Souza. Curso de Direito Internacional Público. Rio de Janeiro: Forense, 2006. p. 292

37. DEL'OMO, Florisbal de Souza. Curso de Direito Internacional Público. Rio de Janeiro: Forense, 2006. p. 292

38. REPUBLICA DEMOCRÁTICA DO TIMOR LESTE. História do Timor Leste.

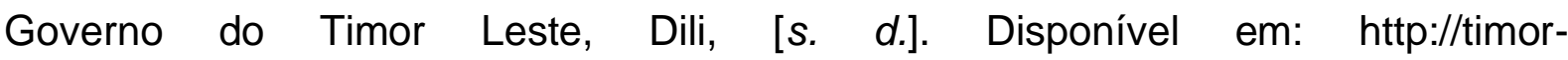
leste.gov.tl/?p=29\&lang=pt. acesso em: 05 maio 2019.

39. TIMOR LESTE; AUSTRÁLIA. Tratado sobre Fronteiras Marítimas entre Timor Leste e Austrália que estabelece as respectivas fronteiras do mar do Timor 
Leste. Nova York: [s.n.], 2018. p. 1. Disponível em: http://www.gfm.tl/wpcontent/uploads/2018/03/Port-Timos-Sea-Maritime-BoundaryTreaty_Portuguese.pdf. Acesso em:05 maio 2018.

40. PEREIRA, Eliana Sofia da Silva. Contributo crítico para a compreensão do regime do Mar de Timor à luz do Direito Internacional. 2013. 87 f. Dissertação. (Mestrado em Ciências Jurídicas Internacionais) Faculdade de direito- Universidade Nova de Lisboa, 2013. p.14-15. Disponível em: https://run.unl.pt/bitstream/10362/17481/1/Pereira_2013.pdf. Acesso em: 01 abr. 2019

41. TIMOR LESTE; AUSTRÁLIA. Tratado sobre Fronteiras Marítimas entre Timor Leste e Austrália que estabelece as respectivas fronteiras do mar do Timor Leste. Nova York: [s.n.], 2018. p. 1. Disponível em: http://www.gfm.tl/wpcontent/uploads/2018/03/Port-Timos-Sea-Maritime-Boundary-

Treaty_Portuguese.pdf. Acesso em:05 maio 2018.

42. TIMOR LESTE; AUSTRÁLIA. Tratado sobre Fronteiras Marítimas entre Timor Leste e Austrália que estabelece as respectivas fronteiras do mar do Timor Leste. Nova York: [s.n.], 2018. p. 1. Disponível em: http://www.gfm.tl/wpcontent/uploads/2018/03/Port-Timos-Sea-Maritime-Boundary-

Treaty_Portuguese.pdf. Acesso em:05 maio 2018.

43. GIBERTONI, Carla Adriana Comitre. Teoria e prática do direito marítimo. Rio de Janeiro: Renovar, 1998. p. 33.

44. TIMOR LESTE; AUSTRÁLIA. Tratado sobre Fronteiras Marítimas entre Timor Leste e Austrália que estabelece as respectivas fronteiras do mar do Timor Leste. Nova York: [s.n.], 2018. p. 1. Disponível em: http://www.gfm.tl/wpcontent/uploads/2018/03/Port-Timos-Sea-Maritime-Boundary-

Treaty_Portuguese.pdf. Acesso em:05 maio 2018.

45. TIMOR LESTE; AUSTRÁLIA. Tratado sobre Fronteiras Marítimas entre Timor Leste e Austrália que estabelece as respectivas fronteiras do mar do Timor Leste. Nova York: [s.n.], 2018. p. 1. Disponível em: http://www.gfm.tl/wp- 
content/uploads/2018/03/Port-Timos-Sea-Maritime-Boundary-

Treaty_Portuguese.pdf. Acesso em:05 maio 2018.

46. TIMOR LESTE; AUSTRÁLIA. Tratado sobre Fronteiras Marítimas entre Timor Leste e Austrália que estabelece as respectivas fronteiras do mar do Timor Leste. Nova York: [s.n.], 2018. p. 1. Disponível em: http://www.gfm.tl/wpcontent/uploads/2018/03/Port-Timos-Sea-Maritime-BoundaryTreaty_Portuguese.pdf. Acesso em:05 maio 2018.

47. TIMOR LESTE; AUSTRÁLIA. Tratado sobre Fronteiras Marítimas entre Timor Leste e Austrália que estabelece as respectivas fronteiras do mar do Timor Leste. Nova York: [s.n.], 2018. p. 1. Disponível em: http://www.gfm.tl/wpcontent/uploads/2018/03/Port-Timos-Sea-Maritime-Boundary-

Treaty_Portuguese.pdf. Acesso em:05 maio 2018.

48. GOMES, Danaciano. Timor Leste: A economia do mar: um contributo para desenvolvimento sustentável. Aveiro: Mare Liberum, 2016. p. 59.

49. REPUBLICA DEMOCRÁtICA DO TIMOR LESTE. História do Timor Leste.

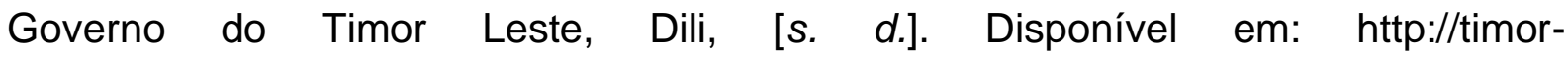
leste.gov.tl/?p=29\&lang=pt. Acesso em: 05 maio 2019.

50. O PRIMEIRO dia no Timor Leste. In: PARCEIROS pela paz. Dili, 06 jul. 2011. Disponível em: https://parceirospelapaz.wordpress.com/category/timor-leste/. Acesso em: 25 maio 2019.

51. REPÚBLICA DEMOCRÁtICA DE TIMOR-LESTE. Ministério das finanças. Orçamento geral do Estado 2018. Díli: Gabinete Ministerial, 2018. p. 7. Disponível em: https://www.mof.gov.tl/wp-content/uploads/2018/08/BB5_Port.pdf. Acesso em: 15 maio 2019.

52. TIMOR LESTE; AUSTRÁLIA. Tratado sobre Fronteiras Marítimas entre Timor Leste e Austrália que estabelece as respectivas fronteiras do mar do Timor Leste. Nova York: [s.n.], 2018. p. 1. Disponível em: http://www.gfm.tl/wp- 
content/uploads/2018/03/Port-Timos-Sea-Maritime-Boundary-

Treaty_Portuguese.pdf. Acesso em: 19 maio 2018.

53. GOMES, Danaciano. Timor Leste: A economia do mar: um contributo para desenvolvimento sustentável. Aveiro: Mare Liberum, 2016.

54. REPUBLICA DEMOCRÁtICA DO TIMOR LESTE. História do Timor Leste.

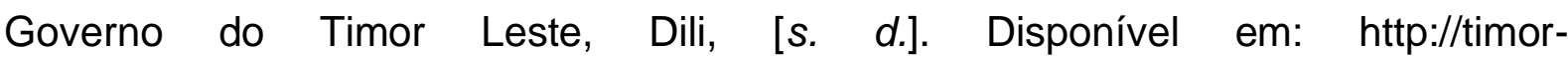
leste.gov.t//p=29\&lang=pt. acesso em: 05 maio 2019

55. TIMOR LESTE; AUSTRÁLIA. Tratado sobre Fronteiras Marítimas entre Timor Leste e Austrália que estabelece as respectivas fronteiras do mar do Timor Leste. Nova York: [s.n.], 2018. p. 1. Disponível em: http://www.gfm.t//wpcontent/uploads/2018/03/Port-Timos-Sea-Maritime-Boundary-

Treaty_Portuguese.pdf. Acesso em: 19 maio 2018.Acessado: 05/05/19

56. TIMOR LESTE; AUSTRÁLIA. Tratado sobre Fronteiras Marítimas entre Timor Leste e Austrália que estabelece as respectivas fronteiras do mar do Timor Leste. Nova York: [s.n.], 2018. p. 1. Disponível em: http://www.gfm.tl/wpcontent/uploads/2018/03/Port-Timos-Sea-Maritime-Boundary-

Treaty_Portuguese.pdf. Acesso em:05 maio 2018.

57. TIMOR LESTE; AUSTRÁLIA. Tratado sobre Fronteiras Marítimas entre Timor Leste e Austrália que estabelece as respectivas fronteiras do mar do Timor Leste. Nova York: [s.n.], 2018. p. 1. Disponível em: http://www.gfm.tl/wpcontent/uploads/2018/03/Port-Timos-Sea-Maritime-Boundary-

Treaty_Portuguese.pdf. Acesso em:05 maio 2018.

58. GOMES, Danaciano. Timor Leste: A economia do mar: um contributo para desenvolvimento sustentável. Aveiro: Mare Liberum, 2016

59. GOMES, Danaciano. Timor Leste: A economia do mar: um contributo para desenvolvimento sustentável. Aveiro: Mare Liberum, 2016. p.114-115. 
60. GOMES, Danaciano. Timor Leste: A economia do mar: um contributo para desenvolvimento sustentável. Aveiro: Mare Liberum, 2016.

61. REPÚBLICA DEMOCRÁTICA DE TIMOR-LESTE. Ministério das finanças. Orçamento geral do Estado 2018. Díli: Gabinete Ministerial, 2018. Disponível em: https://www.mof.gov.tl/wp-content/uploads/2018/08/BB5_Port.pdf. Acesso em: 15 maio 2019.

62. GOMES, Danaciano. Timor Leste: A economia do mar: um contributo para desenvolvimento sustentável. Aveiro: Mare Liberum, 2016.

Enviado: Agosto, 2019.

Aprobado: Diciembre de 2019. 